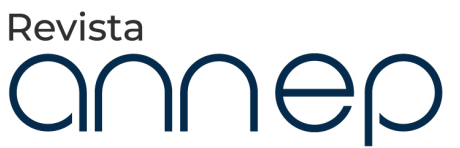

de Direito Processual

\title{
O autor pede... O réu também! Ou da improcedência como procedência
}

\author{
The plaintiff requests (it) ... The defendant also! \\ Merit or dismissal of lawsuit
}

Un derecho de defensa genericamente entendido corresponde a un derecho de acción genericamente entendido. ${ }^{1}$

\section{Resumo}

A resposta direta de mérito do réu no processo de conhecimento é uma forma eficaz de exercício da pretensão à abstenção. Por esta razão, neste caso, o réu, ao responder, deduz pedido que poderá ser julgado procedente ou improcedente.

Palavras-chave: Processo Civil. Pretensão à Abstenção. Pedido na Resposta Direta de Mérito.

\begin{abstract}
Direct response of defendant's merit in the reading of the process is an effective form of claim to exercise abstention. For this reason, the reply of the defendant may cause his plea to be judged either worthy of merit or of dismissal.
\end{abstract}

Keywords: Civil Procedure. Claim to Abstain. Request of Direct Response of Merit.

\section{Introdução}

O título proposto para este artigo, em si, já é uma provocação e um contraponto à célebre frase da processualística pátria, repetida em diversos escritos: "o autor pede, o réu impede". ${ }^{2}$ Para tanto, pretende-se examinar a defesa direta de mérito, aquela que tem por escopo rechaçar o pedido, seja para negar existência do fato jurídico constitutivo do direito do postulante, seja para negar as consequências jurídicas do que o autor deduz. Desta feita, não se tratará aqui da reconvenção, do pedido contraposto ou até mesmo da hipótese de ação dúplice - em que o réu ao apresentar sua defesa, formula pedido, como ocorre nas demandas declaratórias.

Advirta-se. A posição ativa do réu, na resposta, não é novidade na doutrina. Percebe-se isso na obra de Eduardo Couture, por exemplo, entre outros autores.

1 COUTURE, Eduardo J. Fundamentos del derecho procesal civil. 4⿳a ed. Montevideo-Buenos Aires: Julio Cesar Faira, 2002, p. 79.

2 THEDORO JR., Humberto. Curso de direito processual. 47 $7^{\mathrm{a}}$ ed. Rio de Janeiro: Forense, 2007, vol. 1, p. 74. 
Neste passo, procurar-se-á demonstrar que o réu pede, mesmo quando formula sua resposta, ainda que direta de mérito.

Para cumprir esta meta, o tema da improcedência passará, indubitavelmente, pelo estudo da eficácia declaratória das decisões de mérito, já que ela não deixa de ser a resposta a uma pretensão à declaração, como assentado no pensamento de Calmon de Passos. ${ }^{3}$

Outro ponto que será fundamental é a questão envolvendo a pretensão à abstenção, como tratada por Pontes de Miranda, já que ela fornece elementos para que se possa compreender a função ativa do réu ao responder.

Ademais, haverá incursões no modelo kelseniano, juntamente com o contributo de Lourival Vilanova, no intuito de estabelecer como a improcedência se incorpora na configuração da pretensão do réu.

Continuando a análise, verificar-se-á qual a relevância da contribuição de Pontes de Miranda ao estudo das improcedências, máxime com relação às eficácias das sentenças declaratórias.

\section{Apresentando a tese tradicional e sua oposta}

\subsection{Doutrina tradicional}

Antes de qualquer coisa, não se pretende neste pequeno escorço desprezar a contribuição da doutrina tradicional para o tema, mas apenas indicar o modo como ela fundamenta a ideia da defesa direta no bojo do processo.

Como já indicado, tem assento em parte da doutrina a tônica de que só há pedido na ação. A máxima cristalizada nesta perspectiva é: "o autor pede e o réu impede" ou "o autor é quem pede; o réu simplesmente impede (resiste)", ${ }^{5}$ ou ainda, "o réu não exercita uma pretensão, não pede". ${ }^{6}$ A ideia de a contestação ser uma resistência encontra respaldo também no pensamento de Calmon de Passos. ${ }^{7}$ Embora admita o paralelo entre ação e defesa, Araken de Assis, que afirma: "o réu submete-se aos efeitos do processo compulsoriamente, mas reage pelos meios legalmente admissíveis, defendendo-se por intermédio da resposta". 8 Na mesma esteira, Cassio Scarpinella Bueno, que vê um paralelo entre ação e defesa, deixa claro que "é correto o entendimento que o réu não age em juízo (quem o faz é o autor); o réu, diferentemente, reage" (itálicos no original). Já Luiz Guilherme Marinoni, Sérgio Cruz Arenhart e Daniel Mitidiero reconhecem que o réu, ao deduzir sua defesa direta, não tem direito à obtenção a uma tutela do direito material, "mas apenas a tutela jurisdicional que negue a tutela do direito solicitado pelo autor". ${ }^{10}$

Para esta concepção, o réu pede quando faz uso da reconvenção ou pedido contraposto ou contrapedido. Nestes casos, o réu assume a posição de autor e, por sua vez, o autor se torna réu. ${ }^{11}$ Haveria também exercício de pretensão pelo réu, quando na ação dúplice, em que o ato de impedir, por si só, expressa

3 CALMON DE PASSOS, José Joaquim. Comentários ao código de processo civil. 8ª ed. Rio de Janeiro: Forense, 2001, Vol. III (art. 270 a 331), p. 252.

4 THEDORO JR., Humberto. Curso de direito processual. 47쯜. ed. Rio de Janeiro: Forense, 2007, vol. 1, p. 74.

5 CINTRA, Antônio Carlos de Araújo; GRINOVER, Ada Pellegrini; DINAMARCO, Cândido Rangel. Teoria Geral do Processo. São Paulo: Malheiros, 2007, p. 290.

6 DANTAS, Francisco Wildo Lacerda. Teoria geral do processo. 2a ed. São Paulo: Método. 2007, p. 297

7 CALMON DE PASSOS, José Joaquim. Comentários ao código de processo civil. Op. cit., p. 252.

8 ASSIS, Araken. Processo civil brasileiro: parte especial. São Paulo: RT, 2015, vol. III, p. 180.

9 BUENO, Cassio Scarpinella. Curso sistematizado de direito processual civil. 9a ed. São Paulo: Saraiva, 2018 , vol. 1, p. 347.

10 MARINONI, Luiz Guilherme; ARENHART, Sérgio Cruz; MITIDIERO, Daniel. Novo curso de processo civil: Teoria geral do processo. São Paulo: RT, 2015, vol. 1, p. 347.

11 CÂMARA, Alexandre Freitas. Lições de direito processual civil. 23ª ed. São Paulo: Atlas, 2012, vol. 1, p. 373. 
um pedido contrário, como ocorre nas ações declaratórias. ${ }^{12}$ Aqui, o pedido e seu oposto já seriam deduzidos ao se formular a petição inicial.

Em tal contexto, na defesa direta, o réu não age, reage. Esta reação consiste em negar a existência do direito alegado pelo autor, como fica assente de forma clara na lição de Ovídio Baptista. ${ }^{13}$ Além disso, alegam Cintra, Grinover e Dinamarco, que se o réu ao deduzir defesa de mérito pedisse, ser-lhe-ia exigido o adimplemento da condição da ação no interesse de agir. ${ }^{14}$ Acrescentam, ainda, que a resposta do réu não ampliaria o thema decidendum e que o direito ao provimento jurisdicional pretendido pelo autor implica também a análise de fatos excepcionais. Os direitos do réu derivariam do exercício do direito do autor ao provocar a jurisdição. ${ }^{15}$

Ao se referir à defesa, Moacyr Amaral Santos afirma que o direito de ação indica o direito de defesa, ou seja, ambos são direito à prestação jurisdicional, sendo, a defesa, também, um direito subjetivo público, autônomo e abstrato, já que não depende do direito material, podendo-se deduzir defesa mesmo que não haja um contradireito. ${ }^{16}$ No entanto, ambos se diferenciam, pois na ação o autor formula pretensão e o réu resiste. "Não aspira a um direito, mas tão-somente a excluir o alheio."17

Nesta mesma linha, há o pensamento de Fredie Didier Jr. Este assevera que toda demanda irá permitir pelo menos duas soluções: a procedência ou seu oposto. ${ }^{18}$ Desse modo, o réu não necessita pedir a improcedência e, por isso, o magistrado pode rejeitar o pedido, no caso de revelia ou liminarmente, sem ouvir o réu (art. 487, II; e 332,\$1 $1^{\mathrm{o}}$, do CPC).

\subsection{Doutrina que entende que o réu pede, na defesa de mérito}

Partindo para outras sendas, há quem defenda que o réu pede, ou seja, deduz pedido, quando pleiteia a improcedência do pedido. Tal ideia, já mencionada por Cintra, Grinover e Dinamarco, que a rejeitam, ${ }^{19}$ encontra lastro na obra de João Monteiro. ${ }^{20}$ Trilha o mesmo caminho Napoleão Nunes Maia Filho, quanto à pretensão declaratória. ${ }^{21}$

Interessante trabalho é desenvolvido neste sentido por Heitor Sica. Para ele, toda demanda deduzida no processo de conhecimento tem em seu bojo uma declaração, seja ela uma demanda condenatória ou constitutiva. Afinal, é a eficácia declaratória que é recoberta pelo manto da coisa julgada. Acrescenta, ainda, que toda declaração é dúplice, logo, quando o réu deduz a respectiva defesa de mérito, atua como titular de ação dúplice, porquanto pede que seja declarado improcedente o pleito do autor. Argumenta também, o referido autor, que só há pedido quando o réu articula sua defesa; nada impede, entretanto,

12 ASSIS, Araken. Procedimento sumário. São Paulo: Malheiros: 1996, p. 93.

13 SILVA, Ovídio Araújo Baptista da; Gomes, Fábio Luiz. Teoria geral do processo civil. São Paulo: RT, 1997, p. 271.

14 CiNTRA, Antônio Carlos de Araújo; GRINOVER, Ada Pellegrini; DiNAMARCO, Cândido Rangel. Teoria geral do processo. Op. cit., p. 290.

15 CINTRA, Antônio Carlos de Araújo; GRINOVER, Ada Pellegrini; DINAMARCO, Cândido Rangel. Teoria geral do processo. Op. cit., p. 290.

16 "O contradireito é uma situação jurídica ativa - situação de vantagem - exercício como reação ao exercício de um direito. É um direito contra outro direito, assim como antídoto é um veneno contra um veneno. Trata-se de um direito que não é exercido por ação. A afirmação deste direito é feita na defesa, e não na ação.” DIDIER JR., Fredie. Curso de direito processual civil. 17ª ed. Salvador: Juspodivm, 2015, vol. 1, p. 629.

17 SANTOS, Moacyr Amaral. Primeiras linhas de direito processual. 15ª ed., atual. São Paulo: Saraiva, $1993,2^{\circ}$ vol., p. 187.

18 DIDIER JR., Fredie. “Contradireitos, objeto litigioso do processo e improcedência”. In MIRANDA, Daniel Gomes de; CUNHA, Leonardo Carneiro; ALBUQUERQUEJR., Roberto Paulino de. Prescrição e decadência: Estudos em homenagem a Agnelo Amorim Filho. Salvador: Jus Podivm, 2013. p. 186.

19 CINTRA, Antônio Carlos de Araújo; GRINOVER, Ada Pellegrini; DINAMARCO, Cândido Rangel. Teoria Geral do Processo. Op. cit., p. 290.

20 MONTEIRO, João. Teoria do Processo Civil. Rio de Janeiro: Borsoi, 1956, t. I, p. 324.

21 MAIA FILHO, Napoleão Nunes. Estudo Sistemático da Tutela Antecipada. Fortaleza: Gráfica Nacional, 2003 , p. 251. 
que o juiz, sem que haja resposta do réu, possa julgar improcedente, pois a improcedência decorre do reconhecimento de que a eficácia declaratória da sentença de mérito teria caráter dúplice. ${ }^{22}$

\section{O direito de não ser molestado indevidamente - pretensão à abstenção}

Antes de proceder ao exame crítico das duas correntes, faz-se necessário traçar algumas linhas sobre o que aqui se denomina de direito de não ser molestado indevidamente ou pretensão à abstenção.

Como é cediço, todo direito subjetivo confere ao seu titular um poder ante outro sujeito. Na clássica lição de Pontes de Miranda, "cada posição de titular de vantagem, que se confere a alguém, é direito". ${ }^{23}$ Todo direito subjetivo é um poder que se agrega à posição ativa de uma relação jurídica. E toda relação jurídica é consequência de um fato jurídico. ${ }^{24}$

A norma que dá lastro ao aludido fato jurídico é a que decorre da regra que insere no sistema jurídico o denominado "princípio da legalidade". A referida regra, ao estipular que ninguém é obrigado a fazer ou deixar de fazer algo senão em virtude de lei, confere a todos o direito de não ter sua esfera jurídica violada ou ameaçada, salvo nas hipóteses permitidas pelo sistema jurídico. Trata-se de um direito absoluto, já que tem como sujeito passivo toda a coletividade ou sujeito passivo total.

Se alguém pretende que outro faça ou deixe de fazer algo, faz com base na lei. A lei delimita os contornos da esfera jurídica do sujeito de direito. Qualquer agressão ou ameaça a tal esfera é tutelada pelo direito constitucional de ação, previsto no art. $5^{\mathrm{o}}, \mathrm{XXXV}$, da CF/88.

Até aqui, nenhuma dúvida.

O que é interessante é que a posição de não ser molestado, salvo previsão legal, possui uma forte carga declaratória, já que, na sentença, o magistrado deverá reconhecer ou não a existência do referido direito. Além disso, a decisão dará lastro ao exercício da pretensão à abstenção, ou seja, aquela que impõe o dever de não intervir na esfera jurídica de outrem, exceto nas hipóteses previstas pelo ordenamento.

Como assevera Pontes de Miranda, a ação de abstenção pode ser usada para tutelar direito absoluto, direito relativo, bem como direito a não ser molestado, mesmo que não subjetivado. ${ }^{25}$ Com relação à ação de abstenção, Pontes de Miranda lança importante advertência:

A pretensão e a ação de abstenção não são pretensão e ação ex delicto. Nem a culpa lhe é pressuposto necessário. Se culpa existe, é plus. Só exige o ser contrário a direito o ato que se teme, ou cuja continuação se tem por fito evitar. ${ }^{26}$

O que fica presente no excerto trazido à colação é o fato de que a ação de abstenção apenas exige que a atuação do agressor que se pretende abstenção seja contrária a direito, independendo da existência de culpa. Ou seja, haveria pretensão à abstenção contra qualquer espécie de fato jurídica ilícito, como, por exemplo, um ato-fato ilícito - ilícito praticado por absolutamente incapaz.

Neste contexto, a defesa é uma das formas que o sistema confere ao indivíduo de exercitar a pretensão à abstenção, como se verá.

\section{Análise crítica das duas propostas sobre a defesa}

\subsection{Proposta que vislumbra ausência de pedido na defesa direta de mérito}

22 SICA, Heitor Vitor Mendonça. O Direito de Defesa no Processo Civil Brasileiro: Um estudo sobre a posição do réu. São Paulo: Atlas, 2011, p. 205-278.

23 PONTES DE MIRANDA, Francisco Cavalcante. Tratado das ações. São Paulo: RT, 1972, t. I, p. 30.

24 PONTES DE MIRANDA, Francisco Cavalcante. Tratado das ações. Op. cit., p. 29-30.

25 PONTES DE MIRANDA, Francisco Cavalcante. Tratado das ações. Op. cit., p. 150.

26 PONTES DE MIRANDA, Francisco Cavalcante. Tratado das ações. Op. cit., p. 149. 
A proposta desenvolvida por esta corrente tem como cerne a ideia de que o réu, ao deduzir sua defesa direta de mérito, não pede, mas impede. Impedir no sentido de resistir à pretensão autoral. Ademais, toda ação teria em seu bojo a possibilidade de sua negação, possuindo, de certa forma, caráter dúplice. ${ }^{27}$

A maneira de identificar o fenômeno da duplicidade é bastante interessante, e realmente ela ocorre, pois, cada ação, segundo o modelo de cargas de eficácia de Pontes de Miranda, terá sua força declaratória, que pode ser positiva ou negativa, a depender do modo como for reconhecido pelo magistrado. No entanto, a ocorrência do efeito dúplice não apaga a defesa como um agir. Na realidade, ela a afirma.

A articulação feita pelo autor, na petição inicial, é voltada para a procedência do pedido. Trata-se de um discurso finalisticamente dirigido. $\mathrm{O}$ autor, ao deduzir o pedido, não leva para o magistrado uma dúvida, mas um problema, e propõe uma solução. Por esta razão, o advogado exerce função política no processo, já que propõe norma. ${ }^{28}$ Nas palavras atribuídas a Carnelutti, "o primeiro juiz da causa é o advogado".

A proposta veiculada pelo autor pode indicar sua total impertinência com a ordem jurídica. Essas possíveis impertinências não são lógicas, mas jurídico-positivas, já que variam de acordo com cada ordenamento. ${ }^{29}$ Tais impertinências autorizam o magistrado a conhecê-las de ofício. Nada impede que o réu as alegue em sua defesa ou até em outro momento, mas que dela independe, desde que conhecidas a qualquer tempo, tais como: incompetência absoluta, ilegitimidade de parte, decadência, prescrição etc.

Desta forma, as impertinências conhecidas de ofício não equivalem à defesa, enquanto exercício de ação, mas podem ser objeto de defesa, caso não sejam conhecidas de ofício pelo magistrado.

O sistema jurídico permite que o pedido de procedência já traga em seu bojo os elementos necessários para a improcedência, sem atuação do réu. Isso decorre do fato de a ordem jurídica, ao prestar a jurisdição, tutelar o direito subjetivo, na mira de realizar o direito objetivo. Ou seja, seu fim é tutelar a ordem jurídica.

Portanto, a ordem jurídica possibilita que o autor, uma vez não cumpridos os requisitos para a aquisição de um direito, possa ter sua pretensão julgada improcedente pelo Judiciário, independentemente da atuação do réu.

Não se trata de legitimação extraordinária conferida ao magistrado, mas de inexistência, a priori, de preenchimento das condições necessárias para auferir o bem da vida pretendido em juízo. É ônus do autor demonstrar, em dadas circunstâncias, a titularidade do bem da vida que pretende em juízo. Caso isso não ocorra, independentemente da atuação do réu, seu pleito será improcedente.

Há, assim, improcedência que se opera independentemente da atuação do réu, e improcedência que só se pode operar mediante a atuação do réu na defesa.

Passemos ao próximo item.

\subsection{Proposta que vislumbra pedido na defesa direta de mérito}

Tomando caminho diverso, há quem vislumbre pedido, na defesa direta contra o mérito veiculada pelo réu. Demarca bem esta posição Heitor Sica, que afirma haver na defesa o exercício de direito de ação, como faz o autor na inicial. Aduz, em sua linha de raciocínio, que pelo menos o réu exige uma sentença de mérito declaratória negativa. ${ }^{30}$

Neste caso, o réu ao exercitar sua defesa deduz pedido. Não apenas reage, mas pede para não ter sua esfera jurídica atingida pelo autor, já que sua pretensão não encontra respaldo no ordenamento. Assim,

27 DIDIER JR., Fredie. “Contradireitos, objeto litigioso do processo e improcedência”. Op. cit., p. 187.

28 KELSEN, Hans. Teoria pura do direito. 4⿳⺈ ed. Coimbra: Armênio Amado Editor, 1979, p. 472.

29 TERÁN, Juan Manuel. Filosofia del derecho. 18ae ed. Mexico: Porrúa, 2005, p. 81.

30 SICA, Heitor Vitor Mendonça. O Direito de defesa no processo civil brasileiro: Um estudo sobre a posição do réu. São Paulo: Atlas, 2011, p. 249-265. 
a postulação do autor fere este seu direito e corresponde a um ato ilícito; por isso pede que seja livrado do ataque indevido.

Como já ficou evidenciado, a improcedência do pedido não depende necessariamente da atuação do réu. No entanto, há improcedência que decorre da atuação do réu. Neste caso, a lei impõe ao réu a necessidade de se opor à pretensão do autor, sob pena de este se sagrar vencedor. Não se trata de mera reação, mas de ação, em que o réu, na defesa direta de mérito, deduz pedido, exercendo uma pretensão à abstenção.

Desta feita, pode-se julgar improcedente um pedido com ou sem defesa. No entanto, quando ela se faz necessária, há exercício de ação, com pretensão própria. Mas não só declaratória, já que a pretensão à abstenção veicula outras eficácias, como se verá.

Ao deduzir a defesa direta de mérito, o réu alega exercer direito seu, que poderia ser veiculado em demanda autônoma. ${ }^{31}$ Veja-se, por exemplo, o caso dos embargos do devedor, defesa tornada ação autônoma por questão eminentemente formal. Assim, a defesa direta de mérito é uma ação veiculada no bojo de um processo. Noutros termos, a ação tem seu modo de exercício, na defesa.

Neste contexto, o objeto litigioso fixa seus contornos após o prazo para a resposta, quando é dada a oportunidade de o réu deduzir suas razões.

\section{Petição inicial e resposta do réu como pedido}

O autor, na exordial, propõe normas, já que cabe ao advogado escolher dentre as possibilidades as que melhor se ajusta à solução do seu caso. Sempre bom lembrar, que o patrono da parte não leva uma dúvida ao magistrado ou uma pergunta. Leva uma solução, que possui estrutura lógica de norma. Se a solução vai ser aceita ou não depende do desfecho dado ao processo.

Do ponto de vista normativista kelseniano, após o desenho feito por Lourival Vilanova, a norma jurídica teria estrutura bimembre, ou seja, a norma primária estabeleceria a conduta devida e a secundária fixaria a sanção estatal ao ilícito. ${ }^{32}$ Para tanto, será lançada, a seguir, como a estrutura lógica da norma jurídica completa, segundo Kelsen-Vilavonva, corresponde à petição inicial e também à resposta.

Descrever-se-á a estrutura lógica da norma.

Na norma primária, o antecedente (A) será uma descrição de um fato que irá implicar um consequente (C), que implicará uma relação jurídica e suas eficácias, máxime o direito subjetivo. Na norma secundária, uma atitude contrária a direito $(-\mathrm{C})$ terá por consequência a sanção pretendida pelo autor, a ser aplicada pelo Estado ao réu (S). Formalizado: D $(\mathrm{A} \rightarrow \mathrm{C} \mathrm{v}-\mathrm{C} \rightarrow \mathrm{S})$.

$\mathrm{D}=$ functor (ou operador) dever-ser interproposicional que indica tratar-se de uma estrutura normativa;

$\mathrm{A}=$ antecedente da norma primária, que indica fato jurídico lícito;

$\rightarrow=$ dever-ser intraproposicional, que indica a causalidade jurídica e o sinal de implicação;

$\mathrm{C}=$ consequente, que no seu bojo contém uma relação jurídica;

v = ou-includente - não se usa aqui a disjunção;

$-\mathrm{C}=$ antecedente da norma secundária, indica fato jurídico contrário a direito;

$\mathrm{S}=$ sanção pretendida pelo autor. ${ }^{33}$

Percebe-se que a causa de pedir fica delineada na norma primária e no antecedente da norma secundária, já que na primária, o autor descreve o fato jurídico formador de seu direito e a conduta (comissiva ou omissiva) contrária a direito apta a ensejar a sanção estatal.

$31 \quad$ SICA, Heitor Vitor Mendonça. O Direito de defesa no processo civil brasileiro. Op. cit., p. 252.

32 VILANOVA, Lourival. Causalidade e relação. 4ª ed. São Paulo: RT, 2000, p. 188-215.

33 VILANOVA, Lourival. Estruturas lógicas e o sistema do direito positivo. São Paulo: Max Limonad, 1997, p. 95-128. 
O réu, ao deduzir a sua resposta direta de mérito, também, como já mencionado, propõe normas. No caso, haverá, na norma primária, um fato jurídico, a saber, o antecedente (A) que fez nascer uma relação jurídica, consequente (C), e que o ato do autor ao molestá-lo indevidamente - conduta contrária ao direito $(-\mathrm{C})$ - fez nascer a necessidade de uma sanção estatal (S).

Percebe-se assim que a defesa do réu também propõe norma, já que busca a introdução de um comando para solucionar o conflito. A norma proposta pelo réu, no entanto, é diferente da norma proposta pelo autor, já que ambos evocam em seu favor fatos jurídicos distintos, embora correlatos. A alegação de inexistência do direito do autor, como resposta, é, na realidade, afirmação da existência do direito de não ser molestado, uma pretensão à abstenção.

Como dito, a defesa direta de mérito pode ser veiculada como petição inicial em processo autônomo. No entanto, uma vez ajuizada a demanda pelo autor, tal pleito deve ser deduzido na resposta, porquanto este é o instrumento apto ao exercício da pretensão. Perdido o prazo, não se perde o direito material, mas a possibilidade de se deduzir em juízo aquela pretensão. Desta forma, não se poderia ajuizar ação autônoma para substituir a contestação que não se fez no prazo.

\section{O pedido do réu - cargas de eficácia segundo Pontes de Miranda}

Interessante notar que a sanção pretendida pelo réu, na defesa direta de mérito, embora evoque uma pretensão à abstenção, tem por fim primordial uma declaração de que o autor não possui o direito pretendido. A partir da distribuição das cargas de eficácia de Pontes de Miranda, tem-se no caso que a eficácia preponderante (peso 5) da ação proposta pelo réu na defesa direta de mérito é declaratória. Mas a eficácia condenatória se apresenta com força imediata, peso 4, já que, como salientado por Pontes de Miranda, a pretensão à abstenção indica, ao lado da declaração, força condenatória. ${ }^{34}$

Trata-se, portanto, de ação declaratória-condenatória ${ }^{35}$. Percebe-se então a eficácia mediata, peso 3, a mandamental, por conta da preponderância declaratória, já que manda não fazer. ${ }^{36}$ As eficácias mínimas são a constitutiva (peso 2) e a executiva (peso 1). Entretanto, a depender da situação, a executividade pode ter peso 3, caso a sua efetivação implique execução - cumprimento de sentença -, restando, no caso, peso 2 para carga mandamental e 1 para constitutiva.

Registre-se que a força executiva das sentenças declaratórias, já reconhecida por Pontes de Miranda, ${ }^{37}$ encontra registro na obra de Teori Albino Zavascki, que defende tal postura, ${ }^{38}$ sendo reforçado pela legislação do CPC (art. 515, I).

Apesar de não ser objeto de estudo, percebe-se que, por conta das cargas de eficácia, é possível ao magistrado conceder tutela de urgência em favor do réu, que deduz defesa direta de mérito, já que veicula ação com cargas de eficácias distintas que podem ser antecipadas, como bem salienta Fredie Didier Jr. ${ }^{39}$

\section{Notas conclusivas: sentença de (im)procedência}

34 PONTES DE MIRANDA, Francisco Cavalcante. Tratado das ações. Op. cit., p. 149.

35 PONTES DE MIRANDA, Francisco Cavalcante. Tratado das ações. Op. cit., p. 131.

36 Francisco Barros Neto nega a existência da eficácia mandamental nas ações declaratórias. SILVA NETO, Francisco Antônio de Barros e. A antecipação de tutela nos processos declaratórios. Porto Alegre: Fabris, 2005, p. 96

37 PONTES DE MIRANDA, Francisco Cavalcante. Tratado das ações. Op. cit., p. 131.

38 ZAVASCKI, Teori Albino. Título executivo e liquidação. São Paulo: RT, 1999, p.104.

39 "Até mesmo quando simplesmente contesta demanda não-dúplice, pode o réu, preenchidos os pressupostos legais, requerer a antecipação provisória dos efeitos da tutela declaratória negativa (improcedência do pedido do autor) em homenagem ao princípio da isonomia.” DIDIER JR., Fredie, Curso de direito processual civil. 10ª ed. Salvador: Juspodivm, 2015, vol. 2, p. 573 
A sentença que julga improcedente o pedido, em que pese a força da doutrina tradicional, implica reconhecimento de um pedido, quando o réu deduz defesa direta.

Trata-se de reconhecimento do exercício de direito de ação, veiculado por meio da defesa, que tem por objeto, em última análise, o reconhecimento de um direito a não ser molestado de forma indevida pelo autor. É exercício de uma pretensão à abstenção, tão bem analisada por Pontes de Miranda. Assim, a improcedência não deixa de ser procedência, já que, no caso exposto, o réu pede. Ele não reage, age.

Deve-se deixar claro que a improcedência pode decorrer de outros fatores. Aqui a análise se baseou apenas na hipótese da defesa direta do réu. Tais conclusões não têm o condão de ser definitivas, apenas apontam para a discussão de um tema antigo, mas que tem se revelado extremamente importante para a compreensão da ciência processual.

\section{Referências}

ALBUQUERQUE JR., Roberto Paulino de; GOUVEIA FILHO, Roberto P. Campos; PEIXOTO, Ravi; ARAUJO, Gabriela. Ação declaratória incidental no Projeto de Lei no 166/2010 do Senado Federal (Projeto do NCPC): Abolição do instituto? In DIDIER JR. Fredie; BASTOS, Antônio Adonias Aguiar (Coord.). O projeto do Novo Código de Processo Civil: Estudos em homenagem ao Professor J. J. Calmon de Passos. Salvador: Jus Podivm, 2012.

ASSIS, Araken. Procedimento sumário. São Paulo: Malheiros: 1996. Processo civil brasileiro: parte especial. São Paulo: RT, 2015, vol. III.

BUENO, Cassio Scarpinella. Curso sistematizado de direito processual civil. 9ª ed. São Paulo: Saraiva, 2018, vol. 1 .

CALMON DE PASSOS, José Joaquim. Comentários ao código de processo civil. 8aㅡ ed. Rio de Janeiro: Forense, 2001, Vol. III (art. 270 a 331).

CÂMARA, Alexandre Freitas. Lições de direito processual civil. 23⿳⺈冂a ed. São Paulo: Atlas, 2012, vol. 1.

CINTRA, Antônio Carlos de Araújo; GRINOVER, Ada Pellegrini; DINAMARCO, Cândido Rangel. Teoria Geral do Processo. São Paulo: Malheiros, 2007.

COUTURE, Eduardo J. Fundamentos del derecho procesal civil. $4^{\underline{a}}$ ed. Montevideo-Buenos Aires: Julio Cesar Faira, 2002.

DANTAS, Francisco Wildo Lacerda. Teoria geral do processo. 2ª ed. São Paulo: Método. 2007.

DIDIER JR., Fredie. “Contradireitos, objeto litigioso do processo e improcedência”. In MIRANDA, Daniel Gomes de; CUNHA, Leonardo Carneiro; ALBUQUERQUEJR., Roberto Paulino de. Prescrição e decadência: Estudos em homenagem a Agnelo Amorim Filho. Salvador: Jus Podivm, 2013. Regras processuais no Código Civil. $3^{\mathbf{a}}$ ed., Saraiva, 2008. Curso de direito processual civil. 17ํㅗㄹ ed. Salvador: Juspodivm, 2015, vol. 1. Curso de direito processual civil. 10 $0^{\underline{a}}$ ed. Salvador: Juspodivm, 2015, vol. 2.

KELSEN, Hans. Teoria pura do direito. 4ํㅡㄹ ed. Coimbra: Armênio Amado Editor, 1979.

MAIA FILHO, Napoleão Nunes. Estudo sistemático da tutela antecipada. Fortaleza: Gráfica Nacional, 2003.

MARINONI, Luiz Guilherme; ARENHART, Sérgio Cruz; MITIDIERO, Daniel. Novo curso de processo civil: Teoria geral do processo. São Paulo: RT, 2015, vol. 1.

MONTEIRO, João. Teoria do Processo Civil. Rio de Janeiro: Borsoi, 1956, t. I.

PONTES DE MIRANDA, Francisco Cavalcante. Tratado das ações. São Paulo: RT, 1972, t. I. 
SANTOS, Moacyr Amaral. Primeiras linhas de direito processual. $15^{\mathrm{a}}$ Ed., atual. São Paulo: Saraiva, 1993, $2^{\circ}$ vol.

SICA, Heitor Vitor Mendonça. O Direito de Defesa no Processo Civil Brasileiro: Um estudo

sobre a posição do réu. São Paulo: Atlas, 2011.

SILVA, Ovídio Araújo Baptista da; Gomes, Fábio Luiz. Teoria geral do processo civil. São Paulo: RT, 1997.

SILVA NETO, Francisco Antônio de Barros e. A antecipação de tutela nos processos declaratórios. Porto Alegre: Fabris, 2005.

TERÁN, Juan Manuel. Filosofia del derecho. 18ª ed. Mexico: Porrúa, 2005.

THEDORO JR., Humberto. Curso de direito processual. 47를 ed. Rio de Janeiro: Forense, 2007, vol. 1.

VILANOVA, Lourival. Causalidade e relação. 4ª ed. São Paulo: RT, 2000. . Estruturas lógicas e o sistema do direito positivo. São Paulo: Max Limonad, 1997.

ZAVASCKI, Teori Albino. Título executivo e liquidação. São Paulo: RT, 1999. 